\section{A LUZ NA ARQUITETURA E NA GIDADE}

Walter Galvão

Camila D'Ottaviano

A ARQUITETURA E 0 USO DA LUZ A construção de edifícios para o abrigo, atividades religiosas ou armazenamento de mercadorias existe desde os primórdios da urbanização, entre sumérios, egípcios etc. A evolução da arquitetura, com o desenvolvimento de novas tecnologias e diversidade de usos, foi acompanhada de avanços tecnológicos que também impactaram diretamente no desenvolvimento de novas e melhores fontes artificiais de luz.

Se observarmos os primeiros abrigos das civilizaçōes antigas, como as habitações das povoações na China do período neolítico ou mesmo as cabanas celtas, podemos perceber que o fogo era usado sobretudo para o cozimento de alimentos e, em regiōes de invernos rigorosos, para o aquecimento. Como a maior parte das manhãs o homem permanecia na área externa, onde exercia quase todas as atividades do seu dia a dia, recolhendo-se à habitação no período noturno apenas para dormir, poucas eram as preocupações com o fogo nas edificações como fonte de iluminação. Mesmo o uso de aberturas e janelas para aproveitamento da luz natural era um recurso dispensável para o ambiente doméstico, sendo utilizado apenas em templos, palácios e prédios públicos.

Historicamente, alguns efeitos obtidos com a iluminação natural marcaram a arquitetura no decorrer dos séculos. Primeiramente, pode ser citado o templo egípcio do Faraó Ramsés II em Abu Simbel (sec. XII a.C.), onde, por dois dias ao ano, o sol incide sobre as estátuas dos deuses Amon-Rá e Rá-Harakhte, além da escultura que representa o faraó, deixando a imagem de Ptah, uma divindade negativa, sempre na obscuridade. No Panteão romano, de 126 d.C., uma abertura circular no centro da cúpula de cobertura serve para iluminar todo o templo. Com o avanço das técnicas construtivas, como o arcobotante medieval e o vidro, nas igrejas góticas da Idade Média as longas aberturas laterais com vitrais, se tornaram um elemento importante da arquitetura religiosa e consagração do espaço sacro interior. Lemos (1) pondera:

Sobre o vitral das igrejas góticas (...) três propriedades básicas - suporte de imagens sacras, material de riqueza intrínseca assemelhando-se às pedras preciosas e um mistério, pois fulgura sem que haja brilho.

Os avanços tecnológicos na área da arquitetura permitiram também o uso da iluminação natural em edifícios públicos e emblemáticos, como as bibliotecas. A necessidade de iluminação adequada que possibilitasse a leitura sempre foi um desafio para os projetistas e construtores. A biblioteca de Ninive, do século
VII a. C., por exemplo, era tão importante que se localizava no palácio do rei assírio Assurbanípal II. Várias bibliotecas públicas se destacaram na Roma antiga, como a construída por Trajano (53-117 d.C), onde um salão de 30 metros de comprimento era iluminado por grandes janelas. As bibliotecas de mosteiros e conventos da Idade Média (biblioteca-scriptorium) apresentavam inúmeras janelas para iluminar as salas em que os monges se reuniam para ler e estudar.

Pode-se observar (em gravura da Idade Média) São Jerônimo, em sua devoção diária e regeneração da alma, num scriptorium situado ao lado da biblioteca do mosteiro. Esses espaços eram destinados à reprodução de manuscritos [...] a mesa do copista era colocada próxima à janela, de tal forma que a iluminação natural, ao projetar-se no interior da sala, favorecesse a boa reprodução dos livros. A iluminação desses espaços podia ser vista ao olhar a sombra do copista projetada na parede (em gravura já citada), uma indicação de que o arquiteto aproveitava ao máximo a iluminação natural para favorecer o bom uso e função do ambiente (2)

A partir da Revolução Industrial no século XVIII, as cidades cresceram em ritmo vertiginoso. Igualmente aumentou o número de atividades realizadas dentro das edificaçōes. Amplos galpões eram edificados para abrigar indústrias, onde inúmeras pessoas realizavam atividades fabris, necessitando de boa iluminação para o exercício adequado do trabalho. Grandes aberturas serviam para captar o máximo de iluminação natural nas áreas de produção.

No século XIX, as pesquisas na área de saúde pública identificaram que a iluminação natural era importante como fator de prevenção de doenças. Assim, a iluminação natural passou a ser importante também nas habitações. As novas normas e regulações edilícias passaram a exigir aberturas em todos os ambientes de permanência prolongada das habitações. As velhas e insalubres alcovas (espaços para dormir) sem aberturas para o exterior, passavam a ser legalmente combatidas.

Os arquitetos modernistas da primeira metade do século XX incorporaram a iluminação natural em seus projetos como componente cênico e monumental.

Na capela de Notre Dame du Haut (1950), do arquiteto Le Corbusier, as aberturas de diferentes tamanhos e localizadas na fachada sem simetria ou ordem fazem com que a luz natural crie magníficos efeitos formais no interior. Outra obra emblemática é a catedral de Brasília, projetada por Oscar Niemeyer (1958), onde os amplos vitrais da cobertura fazem uma perfeita interação dos fiéis com a divindade. $\mathrm{Na}$ capela do arquiteto mexicano Luis Barragán, na Cidade do México (1952), a luz do entardecer incide por abertura composta de vidros âmbar tangenciando a parede de textura rugosa destacando os efeitos desta rugosidade e fazendo com que uma grande cruz de madeira existente no interior da capela pareça flutuar (3). 


\section{$L U Z / A R$ T I G O S}

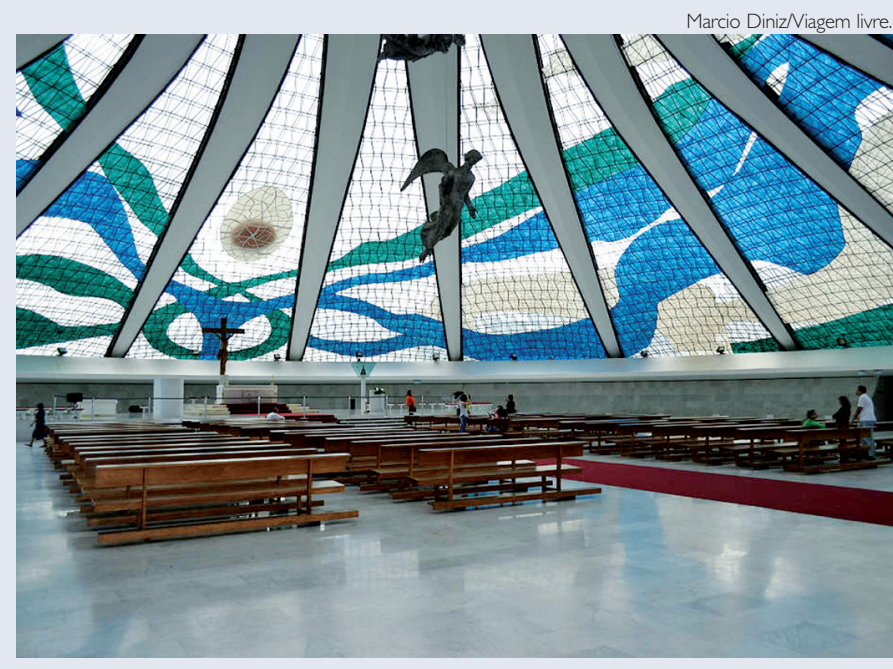

Vitrais da cobertura da catedral de Brasília, projetada por Oscar Niemeyer

No que diz respeito à iluminação artificial, mesmo com o advento da iluminação a gás, os equipamentos de queima de óleo e velas artesanais ainda eram as principais opçōes para a iluminação noturna nas residências. A partir do século XX, a popularização da lâmpada de Thomas Edson fez com que muitas habitações passassem da luz do candeeiro para a elétrica, sem nunca ter utilizado a luz a gás (4). Por outro lado, nas edificações onde se faz necessária a iluminação para a realização de atividades, o advento da iluminação artificial com boa qualidade oriunda da lâmpada elétrica fez com que as jornadas de trabalho se prolongassem para além do entardecer.

No entanto, a falta de preocupaçōes com o gasto de energia no uso da iluminação fez com que ela fosse utilizada indiscriminadamente. Salvo a criação da lâmpada fluorescente, até os anos de 1970 , poucas eram as preocupações na otimização da luz emitida pelas fontes luminosas, fosse melhorando a eficiência energética da lâmpada (lâmpadas que emitissem muita luz com pouco consumo de energia elétrica) ou projetando luminárias que direcionassem a luz das lâmpadas para a área de interesse. Atitudes simples hoje adotadas eram negligenciadas, como a separação de circuitos por setores, sendo que, algumas vezes, quando alguém estava trabalhando isoladamente numa área de um grande salão, todo ele estava iluminado artificialmente.

No início dos anos 1970, a crise do petróleo impactou profundamente o uso da iluminação artificial nas edificaçôes. Com o aumento do custo do petróleo, muitos países tiveram que reduzir o consumo de energia elétrica, pois suas matrizes de geração eram termoelétricas, ou seja, consumiam derivados de petróleo. Surgiram preocupações na sociedade quanto à otimização no uso da iluminação e buscou-se a melhoria na eficiência nos equipamentos. Foram criadas, por exemplo, lâmpadas fluorescentes eletrônicas compactas para que fossem facilmente utilizadas nas habitações, bem como houve o desenvolvimento de lâmpadas de descarga mais eficientes e duráveis para o uso na iluminação pública, como as lâmpadas de vapor de sódio, por exemplo. Nas primeiras décadas do século XXI, as lâmpadas de LED, muito mais duráveis e com baixíssimo consumo de energia, começam a substituir todas as outras e, com a diminuição de seu custo final ao consumidor, passam a tornar-se acessíveis aos usuários de todas as categorias de uso, seja ele residencial, comercial ou industrial.

Por fim, vale citar as preocupações ambientais surgidas a partir dos anos de 1980 e que igualmente impactaram na iluminação das edificaçôes. Programas de controle ao desperdício de energia relacionado ao uso dos sistemas de iluminação artificial tornaramse comuns. O uso da iluminação natural também voltou a ser um elemento importante nos projetos de arquitetura.

A LUZ NAS CIDADES O uso da luz nos espaços externos à habitação e depois nos espaços coletivos e urbanos esteve, desde sempre, ligado à ideia de domínio sobre o espaço e também à noção de proteção e segurança. Existem relatos de que, na Roma antiga, existiam escravos encarregados de acender luminárias e acompanhar pessoas no período noturno, ofício que perdurou até a Idade Média. No entanto, a iluminação das ruas das cidades era, até a Idade Média, primordialmente responsabilidade dos proprietários das casas, que colocavam facultativamente lamparinas ou fogueiras na frente de seus imóveis. Roizemblatt (5) cita algumas esparsas iniciativas de iluminação pública, como dos reis franceses do século XIV, Phillipe V e Jean II, que mandaram instalar velas e lanternas nos portôes de seus palácios. Apenas no século XV, porém, surgiu a primeira tentativa sistemática de iluminação pública quando, em 1417, Sir Henri Barton, prefeito de Londres, ordenou que as casas deveriam manter lamparinas acesas nas suas fachadas (5). Essas iniciativas, no entanto, ainda eram incipientes, pois até então havia pouca movimentação noturna nas cidades.

O crescimento populacional pós-Revolução Industrial nos séculos XVIII e XIX trouxe um incremento na movimentação da vida citadina, prolongando o cotidiano urbano para o período noturno e, muitas vezes, com atividades ilícitas e violentas (7). Mesmo em cidades cujo crescimento não tinha no desenvolvimento da indústria o principal motivo para seu aumento populacional no século XIX, o problema da violência urbana relacionada à vida noturna ocorria. Sobre a cidade do Rio de Janeiro,

Uma bomba populacional abalou o Rio de Janeiro nos treze anos em que a corte portuguesa esteve no Brasil (1808-1821). O número de

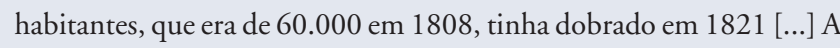
criminalidade atingiu índices altíssimos (...) pouca gente se arriscava a sair desacompanhada à rua depois do anoitecer” (8)

A necessidade de iluminar as ruas das cidades no período noturno tornou-se premente para prover de segurança os espaços urbanos. $\mathrm{Na}$ capital carioca, como resposta para a violência que a assolava nas primeiras décadas do século XIX, o poder público tratou de iluminar as ruas com luminárias onde era utilizado óleo de baleia (8). Cida- 
des como Londres (1807) e Paris (1819) iniciaram experiências de iluminação a gás das áreas públicas. No Brasil, a iluminação pública a gás foi introduzida na segunda metade do século XIX em cidades como São Paulo e Rio de Janeiro, sendo substituída pela iluminação elétrica na primeira década do século XX. Curiosamente, as duas maiores cidades do nosso país não foram as pioneiras na iluminação elétrica dos espaços públicos, cabendo esse ineditismo às cidades de Campos, no estado do Rio de Janeiro, e Rio Claro, em São Paulo, nos anos de 1880 (9).

Com a popularização do automóvel, a iluminação pública passou a ter também a função de iluminar as ruas e calçadas para evitar acidentes entre pedestres e veículos.

Ao longo do século XX, a publicidade passou a fazer parte da iluminação urbana. Aproveitando-se do aumento de atividades no período noturno, o comércio viu na iluminação uma maneira de destacar seus produtos e serviços e atrair clientes. Letreiros nas fachadas dos imóveis, grandes luminosos e outdoors são cada vez mais frequentes nas ruas das grandes cidades ao redor do mundo.

A iluminação pública pode ser usada também como forma de valorização da paisagem urbana, onde, além da iluminação funcional que propicie segurança, facilitando a locomoção e a orientação no período noturno, também ilumine artisticamente marcos urbanos.

CONSIDERAÇÕES FINAIS A luz é vital para a existência do ser humano. A busca por fontes confiáveis de iluminação sempre acompanhou a humanidade ao longo da história. A atração primária do homem pelo fogo estava relacionada com o calor, bem como com o brilho intenso da luz.

Do mesmo modo, o princípio primário da arquitetura foi a busca da melhoraria na qualidade de vida do ser humano. $\mathrm{O}$ momento que o homem resolveu produzir o seu abrigo demonstra que já não se conformava com as adaptaçôes que a natureza fornecia, ou seja, as cavernas não mais atendiam às suas necessidades. Os usos dos edifícios aumentaram e não apenas abrigos passaram a ser produzidos, mas também templos, depósitos, palácios. Durante milênios, o cotidiano no interior dos edifícios ocorria no período diurno pois os humanos dispunham apenas da luz do dia.

Durante a Idade Média, os avanços tecnológicos possibilitaram uma maior utilização da luz natural, em especial nos edifícios religiosos ou emblemáticos. No entanto, nos três últimos séculos, com a introdução dos princípios de produção industrial nas sociedades, aumentaram as demandas de usos nos edifícios, igualmente crescendo a necessidade de evolução na qualidade das fontes artificiais de luz. Ao mesmo tempo, as cidades cresceram e seu cotidiano passou a se prolongar para o período noturno, gerando a necessidade de iluminação também dos espaços públicos.

$\mathrm{Na}$ segunda metade do século XX, não apenas ruas e praças eram iluminadas, mas a luz também passou a ser utilizada como destaque de produtos e serviços, do mesmo modo que marcos urbanos passaram a se destacar no período noturno com o uso da iluminação.
Agradecidos às suas fontes luminosas, os humanos sempre dignificaram seus benefícios. A mitologia grega nominava Prometeu, o titã que roubou o fogo dos deuses e deu aos homens, como "protetor da humanidade" pelo seu feito. Luiz XIV, o mais longevo e prestigiado rei francês, era conhecido como "Rei Sol" pela sua grandeza e magnitude e, mesmo nos dias atuais onde o pensamento racional predomina, as lâmpadas ainda são associadas no ideário comum como uma boa ideia, ou uma "ideia luminosa".

Walter Galvão é arquiteto e urbanista, docente da Universidade Nove de Julho (Uninove), especialista em conforto ambiental e avaliação pós-ocupação (APO) e doutor em arquitetura e urbanismo pela Faculdade de Arquitetura e Urbanismo da Universidade de São Paulo (FAU/USP).

Camila D'Ottaviano é urbanista, docente FAUIUSP. É pesquisadora do Observatório das Metrópoles e do Núcleo de Apoio à Pesquisa, Produção e Linguagem do Ambiente Construido (Napplac). Émembro da diretoria da Associação Nacionalde Pós-Graduação e Pesquisa em Planejamento Urbano e Regional (Anpur) (gestão 2015-2017).

\section{REFERÊNCIAS BIBILIOGRÁFICAS}

1. Lemos, C.A.C.O que éarquitetura. São Paulo:Brasiliense, 2003, p.28.

2. Barbosa, C. V. "Percepção da iluminação no espaço da arquitetura: preferências humanas em ambientes de trabalho". Tese de doutorado. São Paulo: FAU/USP, 2010.

3. Saez, A. M. "Luz, leis e livre-concorrência: conflitos em torno das concessões de energia elétrica na cidade de São Paulo no início do século XX". In: História vol.28 no.2. Franca, 2009.

4. Roizemblatt, I. "Critérios da iluminação elétrica urbana". Tese de Doutorado, São Paulo: Universidade Presbiteriana Mackenzie, 2009.

5. dos Santos, E. R. "A iluminação pública como elemento de composição da paisagem". Dissertação de mestrado. Porto Alegre: UFRGS, 2005.

6. Bresciani, M. S. M. Londres e Paris do século XIX: o espetáculo da pobreza. São Paulo: Brasiliense, 2001.

7. Gomes, L. 1808: Como uma rainha louca, um príncipe medroso e uma corte corrupta enganaram Napoleão e mudaram a história de Brasil e Portugal. São Paulo: Planeta do Brasil, 2007.

8. Kühl,J.C.A.eFerraz,V.M.B."Asusinas de Corumbataí".In:RevistaHistória \& Energia. Patrimônio Arquitetônico da Fundação Patrimônio Histórico da Energia de São Paulo. $2^{a}$ Ed. São Paulo: Fundação Patrimônio Histórico da Energia de São Paulo, 2000. no. 8. 